\title{
A multicentre study of the hospital care of 1500 patients with myelomeningocele*
}

\author{
M Bea Muñoz MD, I Diaz Llopis MD, E Martinez Agullo MD, A Lopez MD, V Garcia \\ Aymerich MD, J V Forner Valero MD
}

Rehabilitation Department, La Fé Hospital, Valencia, Spain.

\begin{abstract}
The purpose of this paper is to describe the medical attention that is given to patients affected by myelomeningocele in Spain. We have used information extracted from the 'Multicentre study of patients suffering from spina bifida in Spain'. This material was collected between 1986 and 1988 from experiences with 1500 patients all over our country. $52.9 \%$ of the patients were male, and $47 \%$ female, and of the total number, $72.2 \%$ were under 15 years of age. Most of these patients attended public hospitals (78.5\%) and on average each one had been admitted about seven times. The cost of hospitalisation of the sample has been assessed. Urology, orthopaedic surgery and rehabilitation are the specialties most involved. The most frequent complications were those related to the urinary system $(66.1 \%)$.
\end{abstract}

Keywords: myelomeningocele; medical problems; hospital assistance.

\section{Introduction}

The chance of survival of newborns suffering from myelomeningocele has improved due to advances in neurosurgery, paediatric surgery and paediatric medicine. ${ }^{1.2}$ Expert management of urological complications has changed the previously ominous long term prognosis. However, this better prognosis has not, unfortunately, been followed by a better quality of life. Patients affected by myelomeningocele have a life with many medical and social problems. ${ }^{3,4}$ The medical management of these patients usually includes care in specialised units, often entailing prolonged and expensive treatment.

Spanish public institutions have promoted a study on the lack of medical and social information about patients affected by myelomeningocele existing in our country. A particular aspect of the study dealing with medical assistance will be presented in this paper.

*This paper was presented at the 30th Annual Scientific Meeting of IMSOP, Stoke Mandeville Hospital, Aylesbury, Bucks, England, 1991.

Correspondence: Manuel Bea Muñoz, C/Brasil 77. pta. 29, 46018 Valencia, Spain.

\section{Methods}

The idea of a multicentre study of patients suffering from spina bifida in Spain was thought of in September 1986, during a scientific meeting of the Spanish Association for the Study and Investigation of Spina bifida and Hydrocephalus. ${ }^{5}$

The purpose was twofold: firstly, to obtain an accurate estimation of the number of patients affected in our country, involving hospitals, private organisations and doctors' files; and secondly, to obtain information about these patients' medical and social problems. The project was supported by the National Institute of Social Services (INSERSO). Part of this study, with additional information about the origin of the sample, has recently been published. ${ }^{6}$

Thirty-three doctors, one teacher, 13 social workers, three nurses and eight psychologists from all over Spain collaborated to compile a questionnaire which included questions on health, education, employment and psychosocial situations. The patients themselves, or their parents (depending on the age or degree to which patients were affected), answered the questionnaire in a personal interview. The most recent data were collected at the end of 1988 . 
The section on medical attention included information about complications, number and types of surgical operations, hospital admissions, usage of public or private facilities and of the specialists who were most often involved.

The level of the neurological lesion was determined by clinical study, or from previous clinical reports. Five groups were distinguished: cervicothoracic, low thoracic (T6-T12), high lumbar (L1-L2), lumbosacral (L3-S2) and sacral (S3-S5).

Health organisation in Spain divides public medical services into primary (general medicine and paediatrics) and specialised. Specialists usually work at hospital level and there is one hospital per health district. Public medicine is funded by the government. Private medicine offers an alternative to public, general and specialised medicine, but in most instances such resources are found only in the main cities.

\section{Results}

The number of patients detected was 1770 . However, only 1500 were actually interviewed, because the study had to be concluded by December 1988, and 270 patients could not be interviewed by this time. Sex distribution in the sample was $52.9 \%$ male and $47.1 \%$ female. Age distribution was as follows: $8.1 \%$ under 2 years of age, $14.4 \%$ between 2 and $5,25 \%$ between 6 and 10 , $25.3 \%$ between 11 and $15,13.1 \%$ between 16 and $20,9 \%$ between 21 and 30 and $5.1 \%$ over 31 years of age. The level of the neurological lesion most commonly found was lumbosacral (L3-S2) (Fig 1).

Of the patients interviewed, $96.1 \%$ were surgically operated, with an average of 4.9 operations per patient. Closure of the neural defect was the operation most commonly performed $(90.5 \%$ of the patients). Such an operation took place during the first 2 days after birth in $59 \%$ of the patients, in $8 \%$ during their third and fourth day of life, in $23 \%$ later, and in $9 \%$ there was no answer to the question.

An average of 6.9 hospital admissions per patient was obtained. The longest admission per patient is shown in Figure 2, and was more than a month in $58.3 \%$ of the cases.

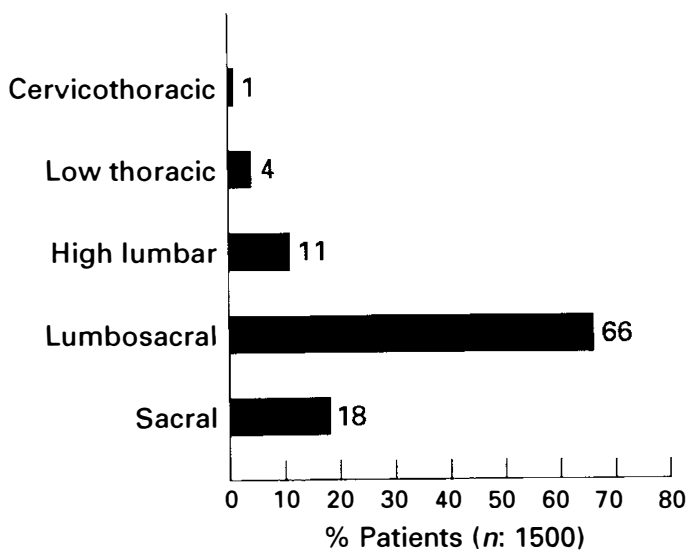

Figure 1 Neurological level in patients with myelomeningocele.

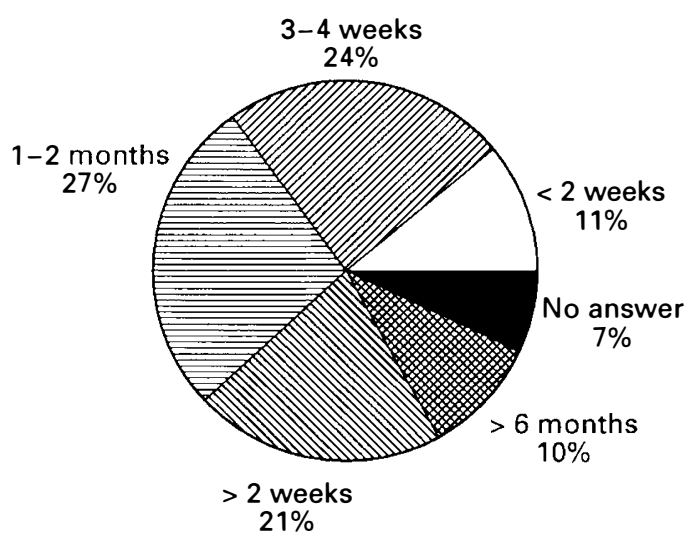

Figure 2 Longest admission per patient. More than a third of the sample had, at least, an admission for more than 2 months.

To obtain an average and estimate cost of hospital services (excluding outpatients), only patients less than 15 years were considered (1080 patients), to avoid excessive dispersion in time. Considering all of the admissions, $57 \%$ of the sample (616 patients) were in hospital for less than 6 months (average 105 days); 17\% (184 patients) stayed between 6 months and 1 year (average 259 days); 9\% (97 patients) between 1 and 2 years (average 515 days); and $10 \%$ (108 patients) more than 2 years (average 910 days). $7 \%$ of the sample (75 patients) did not answer this question. 
The average daily cost per hospital bed in public centres included an estimate of the use of diagnostic techniques. It was calculated from the official rate lists of the Spanish social security system until 1988. The resulting rate was US $\$ 170$.

The cost of admissions over the past 15 years was calculated by multiplying the average admission of every group, the average cost per bed and the number of patients in every group, the result being US $\$ 44,297,070$, with a cost per year of US $\$ 2,953,138$, only from in-hospital care. Prostheses, orthoses and incontinence devices have not been included in the estimation.

Patients suffering from spina bifida are treated in hospitals, with $23.7 \%$ using public general medicine, doctors and paediatricians, and $7.7 \%$ using private local facilities. Public hospitals are mainly used $(78.5 \%$ versus $4.1 . \%$ using private ones) and the cost has thus to be supported mainly by public funds.

The main medical complication was urological, affecting 988 patients of the sample $(66.1 \%)$. In these patients, infections $(87.6 \%)$ and vesicourethral reflux $(32.7 \%)$ were the most common symptoms. The second commonest was hydrocephalus: $927(62 \%) ; 83.8 \%$ were operated on, and have a shunt. Musculoskeletal problems, such as kyphosis, scoliosis or hip dislocation $(44.8 \%)$ and pressure sores $(31.7 \%)$ were less commonly found.

Urology, orthopaedic surgery, rehabilitation and neurosurgery were the most involved specialties (Fig 3). General paediatricians provided only $4 \%$ of the consultations.

\section{Discussion}

A real consensus about treatment criteria of newborn children with myelomeningocele is difficult to achieve. ${ }^{7,8,9}$ However, their survival rates are increasing, and now a high percentage reach adolescence and adulthood $(52 \%$ of our sample), but have severe medical, social and psychological problems.

The majority of our patients were born between 1970 and 1980. A significant

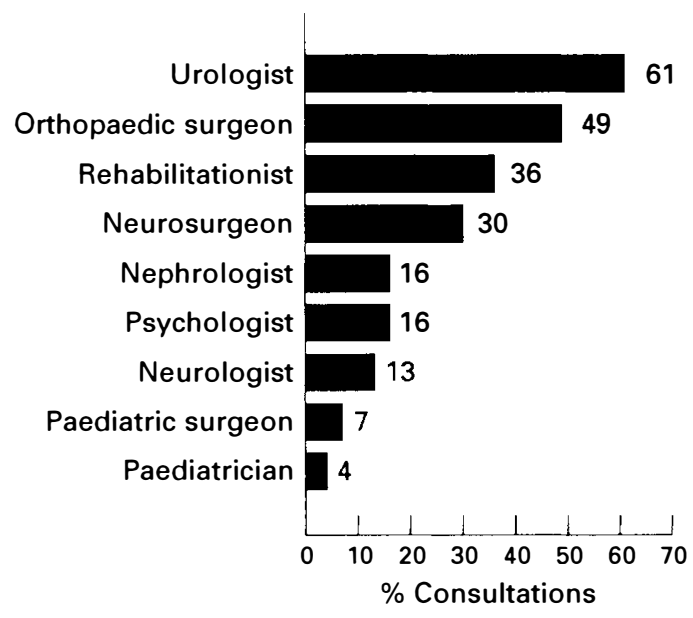

Figure 3 Specialties most frequently consulted by patients with myelomeningocele.

decrease in new cases of myelomeningocele has taken place over the last 5 years. Such a decrease could be explained by screening policies and by a certain natural reduction in numbers from an unknown cause. ${ }^{10}$ Predominance of males, and a lower percentage in hydrocephalus compared with other series $^{11}$ is also striking. A possible explanation for the low incidence of hydrocephalus could be the nature of the sample: a high percentage of severely affected patients may have died during their first years of life, and were thus not included in the study.

The general lack of selection policies in our country during the newborn period, with an early surgical correction of the neural defect in children suffering from myelomeningocele, could explain the survival of patients with a high level lesion (15.6\% thoracic and high lumbar lesions). ${ }^{12,13}$

Public hospitals provide medical attention for a majority of the patients, fewer using local facilities. Hospital doctors should be the providers of specialised treatment during infancy, and should act as supervisors of these patients' management afterwards. Moreover, the access to local facilities should be made easier, with subsequent lower costs. ${ }^{14}$

The experience in Spain with some specialised units has reduced the cost of displacements and the number of repeated 
diagnostic procedures, improving the relationship with the patient and family. ${ }^{15}$ There is a small number of patients consulting general paediatricians $(4 \%)$. Some authors, ${ }^{1,16}$ it is noted, stress the importance of this specialty in the comprehensive treatment of these patients.

Regarding the impact of medical attention on the education of patients suffering from myelomeningocele, the need for repeated medical consultations results in frequent absenteeism from school, affecting their education. ${ }^{17}$ To obtain the best educational results, intensive medical intervention and rehabilitation should have been com- pleted by the time the child starts elementary school. ${ }^{14}$

\section{Conclusions}

A high percentage of patients affected by myelomeningocele will reach adulthood in the next few years. Medical care of these patients is very expensive, and is supported mainly by public resources. Hospital facilities are being used more frequently by our patients. Urological complications have been the most frequent source for medical consultations.

\section{References}

1 Colgan MT (1981) The child with spina bifida. Role of the pediatrician. Am J Dis Child 135: 854-858.

2 McLaughlin JF, Shurtleff DB, Lamers JY et al (1985) Influence of prognosis on decisions regarding the care of newborns with myelodisplasia. N Engl J Med 312: 1589-1594.

3 Rosenbloom L, Cudmore RE (1985) Spina bifida: Do we have the right policies? Arch Dis Child 60: 403-404.

4 Query JM, Reichelt C, Christoferson LA (1990) Living with chronic illness: a retrospective study of patients shunted for hydrocephalus and their families. Dev Med Child Neurol 32: 119-128.

5 Martinez Agulló E, Alberola Cuñat V (1988) Multicentre study of patients suffering from spina bifida. IV National Congress of Spina Bifida, Valencia, Spain: 19-93.

6 Diaz I, Bea M, Martinez Agulló E et al (1993) Ambulation in patients with myelomeningocele: a study of 1500 patients. Paraplegia 31: 28-32.

7 Gross RH, Cox A, Tatyrek R, Pollay M, Barnes WA (1983) Early management and decision making for the treatment of myelomeningocele. Pediatrics 72: 450-458.

8 Evans RC, Tew B, Thomas MD, Ford J (1985) Selective surgical management of neural tube malformations. Arch Dis Child 60: 415-419.

9 Guthklech AN (1986) Aspects of the surgical management of myelomeningocele: A review. Dev Med Child Neurol 28: 525-523.

10 Lorber J, Ward MA (1985) Spina bifida: A vanishing nightmare? Arch Dis Child 60: 1086-1091.

11 Ubeda MI, Morcillo P, Martinez R, Saez A (1988) Prevalence of spina bifida in Comunidad Valenciana. IV National Congress of Spina bifida, Valencia, Spain: 137-141.

12 Villarejo F (1988) Treatment of open and closed spina bifida. IV National Congress of Spina bifida, Valencia, Spain: 277-282.

13 Vila M, Joanes V, Alvarez Garijo JA (1988) Surgical treatment of myelomeningocele. IV National Congress of Spina bifida, Valencia, Spain: 283.

14 Badell-Ribera A (1993) Myelodysplasia. In: Molnar GE, editor. Pediatric Rehabilitation. 2nd edn. Williams \& Willkins, Baltimore: 235 .

15 Guerrero G, Anton R, Gracia J (1988) Need of coordination in the management of spina bifida. IV National Congress of Spina bifida, Valencia, Spain: 165-169.

16 Kanthor $H$ (1982) Can the practising pediatrician provide comprehensive health care for the multiply handicapped child? Clin Pediatr 21: 311-312.

17 Bleck EE (1982) Myelomeningocele, meningocele and spina bifida. In: Bleck EE, Nagel DA, editors. Physically Handicapped Children. A Medical Atlas for Teachers. 2nd edn. Grune \& Stratton, Inc, Orlando: 345-362. 